\title{
APPENDIX XII
}

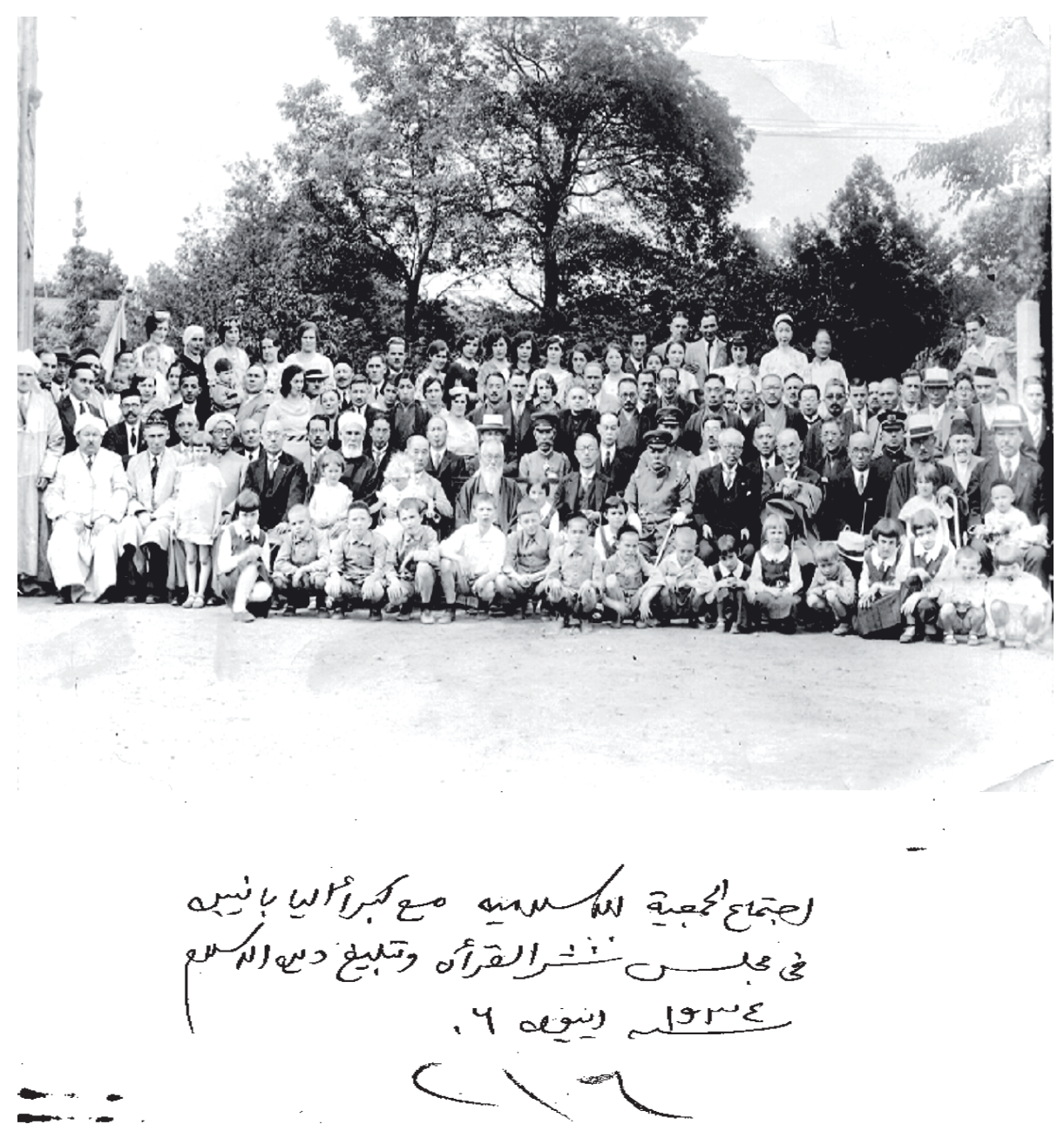

The meeting of the Islamic Society with Japanese notables in the Council of the Qur'ān and Dissimination of the Religion Islam, July I934, Rị̣̂ā's archive, Cairo. 
U. Ryad - 9789047441465

Downloaded from Brill.com๑4/26/2023 08:39:55AM via free access 